\title{
Characterization of high strength mortars with nano alumina at elevated temperatures
}

\begin{abstract}
In this study, the effect of elevated temperatures on chemical composition, microstructure and mechanical properties of high strength mortars with nano alumina was investigated. Mortars with 1, 2 and $3 \%$ nano alumina as cement replacement were prepared and then exposed to $100{ }^{\circ} \mathrm{C}, 200{ }^{\circ} \mathrm{C}, 300{ }^{\circ} \mathrm{C}, 400{ }^{\circ} \mathrm{C}, 600{ }^{\circ} \mathrm{C}, 800{ }^{\circ} \mathrm{C}$ and $1000{ }^{\circ} \mathrm{C}$. XRD, DSC and SEM tests were carried out to identify chemical composition and microstructure changes in the cement matrix after being exposed to elevated temperatures. Residual compressive strength, relative elastic modulus and gas permeability coefficient of samples were also obtained. A brittleness index was defined to monitor changes in brittleness of samples after being exposed to elevated temperatures. Nano alumina enhanced compressive strength of samples up to $16 \%$ and improved residual compressive strength. An increase in the relative elastic modulus, higher energy absorption and lower permeability were also observed when $1 \%$ nano alumina was added.
\end{abstract}

Keyword: Nano Alumina, temperature, mechanical properties, microstructure, mortar 